\title{
Global connections: language policies and international call centers
}

\author{
Kendall A. King
}

Published online: 20 January 2009

(C) Springer Science+Business Media B.V. 2009

When calling (and waiting) for help in some countries, many of us have learned to expect the standard, audio-recorded reminder that 'Your call may be monitored for quality assurance...'. Most of us think little about this delay and if we consider it at all, frame it in terms of how our needs as customers are (or are not) being met at that moment. This thematic issue of Language Policy critically explores what is on the other side of that phrase, that is, what is meant by "quality" in call center translations, how this quality is linked to broader global forces and ideologies, as well as how it is regulated through language policy and negotiated via everyday interactions. In most (but not all, see Duchêne, this issue) cases, call centers involve connecting service-seeking customers from wealthy, English-speaking countries with service-providing workers from more multilingual, less economically powerful states or regions. Managing these cultural, social, and linguistic connections is the central task of the call center employee. The primary good to be produced by the worker is a quality interaction from the perspective of the customer. In many cases, call center services are to be provided without the caller knowing that the call center is in another country; therefore, quality often means that call center workers should sound like the caller. While talking is an important aspect of many jobs in the service sector, in few places is language more central, managed or regulated than in international call centers. Call centers, for this reason, represent an ideal site for critical examination of how language policy is formulated, negotiated and resisted.

Advances in communication and computing technology over the last decade have made international call centers ubiquitous in a wide range of businesses and sites around the globe. Call centers are a highly salient result of globalization, and concomitantly, a rich site for the study of what globalization entails at the individual, interpersonal and interactional level. The articles in this special issue of 
Language Policy explore a wide range of global connections and concerns: What language ideologies shape language policies in particular centers? Who is judged as a legitimate or authentic speaker as a call center worker and how is this reflected in call center policies and practices? Within this highly regulated context, how do global inequities play out through the micro-interactions of individual calls? As large sectors of the economy in many regions of the world now depend on call centers, how are language policies in call centers linked with national educational policies, and what are the appropriate roles of language educators in contexts where call centers dominate the economy? These are some of the questions considered in this thematic issue, the aim of which is to address both how language policies are established and negotiated within call centers as well as how call centers interact with a country's national language policies and with the broader political-economy.

In the first paper of this issue, Selma Katherine Sonntag considers Canadian call center activity (which links to both the U.S. and India) in light of three different theoretical models of cultural globalization (imperialism, hegemony, and cosmopolitanism), and based on the data reviewed, concludes that the linguistic hegemony model is most applicable. Alexandre Duchêne's contribution examines how a tourism call center in Switzerland markets, manages and performs multilingual services, and in particular, how multilingualism operates as a strategic and managerial tool within this context. Eric Friginal then provides qualitative analysis of excerpts of service transactions between a call center in the Philippines and customers in the U.S. to illustrate some of the common communication problems in outsourced call centers; he argues that the communication skills of Filipino agents, together with prevailing U.S. perceptions of outsourcing, determine the success of service encounters. In the last paper, Brian Morgan and Vaidehi Ramanathan offer a dialogic discussion of how call centers intersect with globalization processes, modernity tropes and educational practices and policies. Their interactive, critical discourse analysis of an advertisement to train managers of call centers in India explores how culture is commodified and managed for sale. Reviews of two books also address issues linked to globalization and language policies: Maintaining minority languages in transnational contexts, edited by J. Winter and J. Lo Bianco and Linguistic minorities and modernity: A sociolinguistic ethnography by M. Heller.

A new item, appearing for the first time in this issue, offers a different type of connection. This is the first of a series of interviews between the journal editors and distinguished scholars who played significant roles in the development of the field of language policy. We start off the series here with an interview with Robert Cooper, conducted by Bernard Spolsky and Elana Shohamy. Our next interview, with Joan Rubin, will appear in 8.3.

Turning to the production of the journal, in putting together this thematic issue (and indeed all issues), we are reminded regularly that many of these same global, cross-cultural and economic connections are at play in the production of Language Policy. The Editors and Associate Editors are spread across multiple continents and the journal is managed by offices in the Netherlands. Springer, like so many academic publishers, has outsourced much of the work of the journal production overseas. The technical support for the submission and external review of the 
journal is handled by a firm in the Philippines; proof-reading and type-setting is conducted by a different firm in India. We have never met our Indian or Filipino colleagues, nor even had the chance to exchange words by phone, but are in daily (often hourly) communication by email. We are permanent characters in each other's email inboxes, as we attempt, with varied levels of success, to cooperatively understand each other's requests, constraints, and needs in the different phases of the production of Language Policy. This communication is detailed and intense but also anonymous on some level; yet their support and collaboration is invaluable in keeping the journal going. These interactions serve as daily reminders of our all of global connections as well as the challenges, complications, and learning opportunities these connections entail. 